\title{
STUDY OF HEPATOBILIARY DUCTAL SYSTEM BY LAPAROSCOPIC CHOLANGIOGRAPHY
}

\author{
Mahesh Gupta ${ }^{1}$, Manoj Gupta², Pooja Gupta ${ }^{3}$ \\ ${ }^{1}$ Associate Professor, Department of Surgery, Rama Medical College Hospital and Research Centre, Mandhana Kanpur, Uttar Pradesh. \\ ${ }^{2}$ Senior Consultant, Department of Surgery, SGL Charitable Hospital, Jalandhar. \\ ${ }^{3}$ Senior Consultant, Department of General Medicine, SGL Charitable Hospital, Jalandhar.
}

ABSTRACT
BACKGROUND
Laparoscopic cholecystectomy is a routine procedure in our clinical practice and laparoscopic cholangiography has been
performed during laparoscopic cholecystectomy to detect ductal anomalies and unsuspected common duct stones.

\section{AIMS AND OBJECTIVES}

Although laparoscopic cholecystectomy is a routine procedure in our clinical practice, laparoscopic cholangiography was performed during laparoscopic cholecystectomy to detect ductal anomalies and unsuspected common duct stones.

\section{MATERIAL AND METHODS}

Twenty consecutive patients with symptomatic gall stone disease undergoing routine laparoscopic cholecystectomy were included in the study. All the patients were evaluated and standard laboratory and radiographic tests were obtained. Under general anesthesia, standard four port technique of laparoscopic cholecystectomy was used in all the cases. After completion of cholangiography, self-retention cone was retracted and catheter was removed under vision. Haemostasis and duct integrity was confirmed. Further cholecystectomy was performed in routine fashion.

\section{RESULTS}

It was observed that the female patients were three times more as compared to the male patients and more than $80 \%$ of the patients were above the age of 30 years. Time taken for laparoscopic cholecystectomy and cholangiography was in the range of 100 180 minutes (Mean 141 minutes), whereas time taken for only laparoscopic cholangiography was in the range of 28-45 minutes. Intraoperatively on cholangiography 17 patients were found to have normal anatomy of hepatobiliary system, whereas 2 patients had accessory cystic artery and 1 patient was found to have phrygian cap and no one had unsuspected common duct stone. There was no mortality in our series and no postoperative complication attributable to cholangiography could be demonstrated.

\section{CONCLUSION}

In routine cholangiography because of low yield of unsuspected common duct stones, extraoperative time and cost, cholangiography can be performed selectively in patients with common duct pathology. But for the teaching of surgical residents and for development of technical skills to address common duct stones routine cholangiography should be performed.

\section{KEYWORDS}

Laparoscopic Cholangiography, Laparoscopic Cholecystectomy, Gall Bladder, Cholecystectomy.

HOW TO CITE THIS ARTICLE: Mahesh Gupta, Manoj Gupta, Pooja Gupta. "Study of Hepatobiliary Ductal System by Laparoscopic Cholangiography." Journal of Evolution of Medical and Dental Sciences 2015; Vol. 4, Issue 99, December 10; Page: 16447-16450, DOI: $10.14260 /$ jemds/2015/2440

\section{INTRODUCTION}

Approximately, $10 \%-15 \%$ of adult population suffer from gallstone disease and approximately 5 Lac gall bladders are removed annually. Common bile duct stones occur in $10 \%$ $20 \%$ of these cases and $5 \%-7 \%$ of these stones remain undetected on pre-operative clinical evaluation. ${ }^{1}$ Lahey (1936) admitted that he had left a stone in common bile duct in one out of every 10 patients subjected to cholecystectomy. Continuous efforts were made to decrease the number of negative common bile duct explorations, while increasing the positive exploration rate till the introduction of operative

Financial or Other, Competing Interest: None.

Submission 20-11-2015, Peer Review 21-11-2015,

Acceptance 02-12-2015, Published 10-12-2015.

Corresponding Author:

Dr. Mahesh Gupta,

Associate Professor, Department of Surgery,

Rama Medical College Hospital and Research Centre,

Mandhana, Kanpur,

Uttar Pradesh.

E-mail:gm982003@yahoo.co.in

DOI:10.14260/jemds/2015/2440 cholangiography by Mirrizzi in 1931.2 Since then operative cholangiography has become an important part of cholecystectomy, either practiced in a routine or in a more selective manner. In recent years, laparoscopic cholecystectomy has become the new 'Gold Standard' technique for removing the gall bladder.

The need for laparoscopic cholangiography is felt more as laparoscopy takes away the surgeon's three dimensional perspective and eliminates tactile clues to evaluate common bile duct. Also in cases of bile duct injuries during laparoscopic cholecystectomy operative cholangiogram seems useful to provide an accurate "Road map" to define the pertinent anatomy and immediate detection of bile duct injuries when it occurs. Routine cholangiography is advocated to detect unsuspected common duct stones, which are seen in 5\%-10\% of cases. $1,3,4$

Routine performance of cholangiography improves the ability to perform it in difficult situations and develop technical skills to detect the stones in common bile duct. Although laparoscopic cholecystectomy is a routine procedure in our clinical practice, laparoscopic cholangiography was 
performed during laparoscopic cholecystectomy to detect ductal anomalies and unsuspected common duct stones.

\section{MATERIALS AND METHODS}

Twenty consecutive patients with symptomatic gall stone disease undergoing routine laparoscopic cholecystectomy at Rama Medical College Hospital and Research Centre, Kanpur, UP, were included in this study. However, patients with proven common bile duct stones, history of cholangitis, obstructive jaundice, acute pancreatitis, cholecystoenteric fistula, previous upper abdominal surgery, malignancy of gall bladder, severe cardiopulmonary disease were excluded from this study.

All the patients were evaluated and standard laboratory and radiographic tests were obtained. Under general anesthesia, standard four port technique of laparoscopic cholecystectomy was used in all the cases. However, after dissecting the Calot's triangle and identifying the cystic duct clearly, it was clipped close to the neck of gall bladder with a clip and a straight scissor was introduced through the epigastric port and an opening was made into cystic duct close to the clip towards gall bladder.

The introducer consisting of $13 \mathrm{~cm}, 13 \mathrm{G}$ sheath and needle was advanced into the peritoneal cavity in the right upper quadrant of the abdomen, directly in line with cystic duct across the shortest possible distance to the opening in cystic duct. Once in peritoneal cavity the needle was withdrawn from the sheath and a rigid $6 \mathrm{~F}$ cholangiocatheter with 45-degree angle near $3 \mathrm{~F}$ tapered tip was passed through the sheath into the peritoneal cavity and introduced into the opening in the cystic duct by manipulating the end of the catheter that was outside the body.

Once in the duct, an expanding anchoring mechanism was activated to secure it and seal the duct opening by pushing a ratchet on the handle of cholangiography catheter. After completion of cholangiography, self-retention cone was retracted and catheter was removed under vision. Haemostasis and duct integrity was confirmed. Further cholecystectomy was performed in routine fashion.

\section{RESULTS}

In our study of 20 patients who had undergone routine laparoscopic cholangiography, it was observed that the female patients were three times more as compared to the male patients and more than $80 \%$ of the patients were above the age of 30 years, while $60 \%$ of the patients were falling in the range of 30-50 years (Table 1,2).

Nearly $90 \%$ of patients presented with pain in the right hypochondrium and ultrasound of the abdomen demonstrated the presence of stones in all the patients. Time taken for laparoscopic cholecystectomy and cholangiography was in the range of 100-180 minutes. (Mean 141 minutes), whereas time taken for only laparoscopic cholangiography was in the range of 28-45 minutes, mean 34 minutes. (Table 3,4).

In 2 cases laparoscopic cholangiography was not possible due to presence of small, fibrosed cystic duct in one case and disruption of cystic duct during cannulation in another case. Intraoperatively on cholangiography, 17 patients were found to have normal anatomy of hepatobiliary system, whereas 2 patients had accessory cystic artery and 1 patient was found to have phrygian cap and no one had unsuspected common duct stones (Table 5). There was no mortality in our series and no postoperative complication attributable to cholangiography could be demonstrated. The postoperative stay in 20 patients of laparoscopic cholangiography was 1-4 days (Mean 2.45 days), whereas total average cost per cholangiogram in 20 patients of laparoscopic cholangiography was Rs. 1050.

\section{DISCUSSION}

Laparoscopic cholecystectomy (LC) is the treatment of choice in symptomatic gallbladder diseases. However, the incidence of bile duct injuries were found to be two to five times higher than open cholecystectomies in the initial series reported in the literature and this was mainly due to the learning curve associated with this technique.5,6

Also early division of cystic duct in LC is more dangerous than traditional open cholecystectomy and this has led a number of authors to perform routine operative cholangiography. 7,8 The authors who favor routine use of intraoperative cholangiography suggest many anatomical anamolies, which are found during cholangiography and such findings may avoid numerous complications. ${ }^{9}$

However, it is unclear that such recognition truly prevents bile duct injuries and these injuries are reported in the literature despite the use of intraoperative cholangiography. Not only this but the instrumentation done during intraoperative cholangiography may lead to bile duct injuries, especially in spite of clipping the cystic duct one may clip and incise the CBD to introduce the cholangiocatheter and this necessitates some form of repair.

Intraoperative cholangiography may suggest presence of short cystic duct, which is a common variant and is believed to cause injury during LC. To avoid such complications, we suggest that the dissection should be started at the infundibulo-cystic junction and the duct structures must be clearly defined before the application of clips. In our series, we did not encounter any bile duct injury and this was probably due to the technique followed by us and the selection of cases.

However, in one case we could not negotiate cystic duct due to fibrosis and in another case it got disrupted while canulation and the procedure of cholangiography was abandoned. Routine use of intraoperative cholangiography is also advocated by many authors to detect the presence of unsuspected stones in CBD even before the introduction of laparoscopy.

The presence of unsuspected stones range between $1.2 \%$ to $12.4 \%$, which are detected on routine intraoperative cholangiography and $0.3 \%$ of residual stones in series suggesting only cholecystectomy without cholangiography. ${ }^{10}$ 12 However, false positive cholangiograms range between $2 \%$ to $16 \%$ and this leads to unnecessary increase in the conversion rates of laparoscopic cholecystectomies into open cholecystectomies. ${ }^{9}$ Furthermore, removal of these bile duct stones poses a major problem during laparoscopic procedures and there is high potential for bile duct injuries, especially in undilated ductal system. This has led to the introduction of pre- and post-operative endoscopic retrograde cholangiography. ${ }^{13-16}$

In our study we did not find any unsuspected stones in CBD and this may be attributed to the number of cases in which we had performed routine intraoperative cholangiography. Barkun et al. (1993) found an average of 24-minute increase in operating time while performing routine cholangiography during LC and Soper (1992) had identified increase in the cost of this procedure by 700 U.S. dollars. ${ }^{17,18}$ In our study, time 
taken for laparoscopic cholangiography was in the range of 2845 minutes, which was almost in accordance with their studies and the total average cost per cholangiogram was Rs. 1050 (INR) with an average hospital stay of 1-4 days. With this we recommend the use of routine cholangiography, especially in teaching of surgical residents to develop the technical skill and define the anatomy of extrahepatic biliary system to avoid and manage intraoperative bile duct injuries.

\section{CONCLUSION}

In summary, we performed operative cholangiography routinely in 20 consecutive cases of laparoscopic cholecystectomy. The success rate of procedure in our series was $90 \%$. In $15 \%$ of cases anomalies of hepatobiliary system was found, among the most common was accessory cystic artery. No case of ductal anomaly was found. Operative cholangiography took on an average 34 minutes.

There was no false negative or false positive study in our series. No case of unsuspected common bile duct stone could be detected. Only one patient had intraoperative complication in the form of cystic duct disruption that was managed immediately. The cost of an operative cholangiogram was on an average Rs. 1050.

The data suggests that laparoscopic cholangiography is an easy, safe and accurate technique. Moreover, it provides an excellent definition of biliary anatomy for safety purposes. In routine cholangiography because of low yield of unsuspected common duct stones, extraoperative time and cost, cholangiography can be performed selectively in patients with common duct pathology. But for the teaching of surgical residents and for development of technical skills to address common duct stones, routine cholangiography should be performed.

\begin{tabular}{|c|c|}
\hline Sex & No. of Patients \\
\hline F & 15 \\
\hline M & 5 \\
\hline Ratio & $3: 1$ \\
\hline \multicolumn{2}{|c|}{ Table 1: Sex Distribution of 20 Laparoscopic } \\
Cholecystectomy Patients
\end{tabular}

Age distribution of 20 Laparoscopic Cholecystectomy patients

\section{REFERENCES}

1. Scott JA. Gallbladder Surgery [online]. Available at: http://www.everydayhealth.com/gallbladder/surgery/.

2. Mirizzi PL. Operative Cholangiography, its contribution to the physio-pathology of the common bile duct. The Lancet 1938;232:366-369.

3. Metcalfe MS, Ong T, Bruening $\mathrm{MH}$, Iswariah $\mathrm{H}$, WemyssHolden SA, Maddern GJ. Is laparoscopic intraoperative cholangiogram a matter of routine? Am J Surg 2004;187:475-481.

4. Massarweh NN, Flum DR. Role of intraoperative cholangiography in avoiding bile duct injury. J Am Coll Surg 2007;204:656-664.

5. NIH Consensus conference. Gallstones and laparoscopic cholecystectomy. Jama 1993;269:1018-1024.

6. Moossa AR, Easter DW, Van Sonnenberg E, Casola G, D'Agostino H. Laparoscopic injuries to the bile duct. A cause for concern. Annals of surgery 1992;215:203-208.

\begin{tabular}{|c|c|}
\hline Age Group (Years) & No. of Patients \\
\hline$<20$ & 2 \\
\hline $20-30$ & 2 \\
\hline $30-40$ & 5 \\
\hline $40-50$ & 6 \\
\hline $50-60$ & 3 \\
\hline$>60$ & 2 \\
\hline Total & 20 \\
\hline Mean & 41.4 years \\
\hline Range & $12-68$ years \\
\hline \multicolumn{2}{|c|}{ Table 2: Age Distribution } \\
\hline
\end{tabular}

Time taken for Laparoscopic Cholecystectomy and Cholangiography

\begin{tabular}{|c|c|}
\hline Surgery Time (Mins) & No. of Patients \\
\hline $90-120$ & 9 \\
\hline $120-150$ & 4 \\
\hline $150-180$ & 7 \\
\hline Mean & 141 mins \\
\hline Range & $100-180$ mins \\
\hline \multicolumn{2}{|c|}{ Table 3: Time Taken for Surgery } \\
\hline
\end{tabular}

Time taken for Laparoscopic Cholangiography

\begin{tabular}{|c|c|}
\hline In Minutes & No. of Patients \\
\hline $25-30$ & 4 \\
\hline $30-35$ & 7 \\
\hline $35-40$ & 5 \\
\hline $40-45$ & 2 \\
\hline Total & 18 \\
\hline Mean & 34 mins \\
\hline Range & $28-45$ mins \\
\hline Table 4: Cholangiography Time \\
\hline
\end{tabular}

\begin{tabular}{|c|c|}
\hline Normal Anatomy & $\mathbf{1 7}$ \\
\hline Accessory cystic artery & 2 \\
\hline Phrygian cap & 1 \\
\hline Common duct stones & 0 \\
\hline Table 5: Operative Findings No. of Patients \\
\hline
\end{tabular}

7. Berci G, Sackier JM, Paz-Partlow M. Routine or selected intraoperative cholangiography during laparoscopic cholecystectomy? Am J Surg 1991;161:355-360.

8. Sackier JM, Berci G, Phillips E, Carroll B, Shapiro S, PazPartlow M. The role of cholangiography in laparoscopic cholecystectomy. Arch Surg 1991;126:1021-1025; discussion 1025-1026.

9. Lillemoe KD, Yeo CJ, Talamini MA, Wang BH, Pitt HA, Gadacz TR. Selective cholangiography. Current role in laparoscopic cholecystectomy. Annals of surgery 1992;215:669-674; discussion 674-666.

10. Glenn F, McSherry CK. Calculous biliary tract disease. Current Problems in Surgery 1975;12:1-38.

11. Mills JL, Beck DE, Harford FJ, Jr. Routine operative cholangiography. Surgery, gynecology \& obstetrics 1985;161:343-345.

12. Kitahama A, Kerstein MD, Overby JL, Kappelman MD, Webb WR. Routine intraoperative cholangiogram. Surgery, gynecology \& obstetrics 1986;162:317-322. 
13. Neoptolemos JP, Davidson BR, Shaw DE, Lloyd D, CarrLocke DL, Fossard DP. Study of common bile duct exploration and endoscopic sphincterotomy in a consecutive series of 438 patients. The British journal of surgery 1987;74:916-921.

14. Schwab G, Pointner R, Wetscher G, Glaser K, Foltin E, Bodner E. Treatment of calculi of the common bile duct. Surgery, gynecology \& obstetrics 1992;175:115-120.

15. Sivak MV. Endoscopic management of bile duct stones. The American Journal of Surgery 1989;158:228-240.

16. Barkun AN, Barkun JS, Fried GM, et al. Useful predictors of bile duct stones in patients undergoing laparoscopic cholecystectomy. McGill Gallstone Treatment Group. Annals of surgery 1994;220:32-39.
17. Barkun JS, Fried GM, Barkun AN, et al. Cholecystectomy without operative cholangiography. Implications for common bile duct injury and retained common bile duct stones. Annals of surgery 1993;218:371-377; discussion 377-379.

18. Soper NJ, Dunnegan DL. Routine versus selective intraoperative cholangiography during laparoscopic cholecystectomy. World journal of surgery 1992;16:1133-1140. 